\title{
Prevalence of Pulmonary Tuberculosis among the suspected patients visiting tertiary care hospital in Birgunj, Nepal
}

\author{
Shrestha $S^{1}$, Shakya $B^{1}$ and Shrestha $P^{2}$
}

Department of Clinical Microbiology and Tuberculosis Centre, National Medical College, Birgunj, Nepal

${ }^{1}$ Central Department of Microbiology, Tribhuvan University, Kirtipur, Kathmandu, Nepal,

${ }^{2}$ Spinal Injury rehabilitation Center, Saagha, Banepa, Kavre,Nepal.

\section{ABSTRACT}

Background and Objectives: Mycobacterial disease continues to cause high morbidity and mortality and is a major public health problem in Nepal. Bacteriological examination of sputum is the cornerstone in the diagnosis of pulmonary tuberculosis in the developing world. This prospective study was carried out with an objective to evaluate the prevalence of pulmonary tuberculosis among the patients visiting National Medical College Teaching Hospital by ZiehlNeelsen (Zn) staining microscopy.

Material and Methods: The study was cross-sectional study. Three consecutive early morning sputum collected from 626 patients were subjected to $\mathrm{Zn}$ staining and observed under oil immersion.

Results: Among 626 patients, $85(13.57 \%)$ were found to be Acid fast positive by Zn staining microscopy. Of total suspected patients, $16.0 \%$ of male and $8.7 \%$ of female were infected, common among $41-60$ years group (17.2\%) followed by $21-40$ years $(12.6 \%)$ and multibacillary cases was $71.8 \%$.

Conclusion: The prevalence of pulmonary tuberculosis among National medical college teaching hospital was found to be higher than the Nation pulmonary tuberculosis detection rate, most commonly infecting males.

Key words: Pulmonary tuberculosis, Prevalence, Zn staining, Nepal

\section{INTRODUCTION}

Tuberculosis (TB), one of the major air-borne infectious bacterial disease is of significant pub- lic health importance worldwide [1]. A global emergency was declared by WHO in the year 1993, kills 8000 people a day $(2.3$ million 
people each year) [2]. Majority (95\%) of these cases and $98 \%$ of tolls fall only in developing countries $[3,4]$. About $45 \%$ of Nepal population suffers from this disease. Every year 44,000 people develop active tuberculosis; of whom 20,000 are infectious pulmonary disease resulting 8-11 thousand death range in Nepal are believed [5].

The history of sputum examination dates back to 1882 when Robert Koch discovered the tubercle bacillus and confirmed the bacterial etiology of tuberculosis $[6,7]$. The bacilli in the sputum can be detected by Zn staining which is commonly used throughout the world and still remains the standard method against which new tests must be measured [7, 8]. The smears stained by Zn staining method can detect bacilli when they are at the order of $10^{5} /$ milliliter $(\mathrm{ml})$ of sputum $[9,10]$. Zn staining microscopy is cheaper and more useful for laboratory diagnosis of disease in poor and developing countries like Nepal [11] and also it is simple and rapid [11, 12]. Thus for the developing countries with a large numbers of cases and financial constraints, evaluation of rapid and inexpensive diagnostic methods like demonstration of acid fast bacilli in smears is of great importance [13].

\section{MATERIAL AND METHODS}

Settings: This study was conducted in Tuberculosis laboratory at National Medical College Teaching Hospital, Birgunj, Nepal.

Sputum samples: Routine fresh clinically suspected pulmonary TB patients referred from outpatient department (OPD) to Tuberculosis laboratory were included. Three consecutive sputum samples from 626 patients were collected for 1 year (July 18, 2007 to July 17, 2008).
Smear preparation: Sputum sample was smeared evenly with an uneven end of broom stick on the slide, the smear size being $2 \mathrm{cmX} 3 \mathrm{~cm}$ and it was not too thick. The smear was air dried. Then was methanol fixed and then the slides were placed in serial order on the staining rack with the smeared slides facing upward ensuring slides do not touch each other.

Zn-staining procedure: The procedure was described by WHO laboratory guidelines [11]. The fixed smears were flooded with the solution of 1 percent carbol fuchsin then heated underneath until vapors start rising and were allowed to stand for 5 minutes. The smears were then rinsed with water and counterstained with Methylene blue solution and followed by air drying. The slides were then examined under microscope in X100 oil immersion.

\section{Microscopy reports}

In recording and reporting of microscopic results, the following reporting scale was used for $\mathrm{Zn}$ staining as per guidelines given by WHO [14].

\begin{tabular}{|l|c|}
\hline $\begin{array}{l}\text { No. of Bacilli seen in a } \\
\text { smear }\end{array}$ & Result reported \\
\hline $\begin{array}{l}\text { No AFB per } 300 \text { oil } \\
\text { immersion fields }\end{array}$ & Negative \\
\hline $\begin{array}{l}\text { 1-9 AFB per } 100 \text { oil } \\
\text { immersion fields }\end{array}$ & $\begin{array}{c}\text { Record the exact } \\
\text { number }\end{array}$ \\
\hline $\begin{array}{l}\text { 10-99 AFB per } 100 \text { oil } \\
\text { immersion fields }\end{array}$ & $1+$ \\
\hline $\begin{array}{l}1-10 \text { AFB per } 10 \text { oil } \\
\text { immersion fields }\end{array}$ & $2+$ \\
\hline $\begin{array}{l}>10 \text { AFB per oil } \\
\text { immersion field }\end{array}$ & $3+$ \\
\hline
\end{tabular}


The number of AFB found is an indication of the degree of infectivity of patient as well as the severity of tuberculosis. (For the present study $2+$ and $3+$ were classified as multibacillary and $1+$ and scanty as paucibacillary) [15].

Statistical analysis: The results were analysed by using the chi-square test $\left(\mathrm{chi}^{2-}\right.$ test). The data were determined to have statistically significant at 95 percent confidence interval if the $P$ value was less than 0.05 .

\section{RESULTS}

In the study among 626 suspected patients 85 patients $(13.6 \%)$ were found to have pulmonary tuberculosis. Out of 626 patients included under the study, 418 were male (66.8\%) and 208 were female $(33.2 \%)$ of which $16.0 \%$ of male and $8.7 \%$ of female were infected.

The prevalence rate was highest among 41-60 years group (17.2\%) followed by 21-40 years $(12.6 \%)$ and least at the age group of upto 20 years (Table-2).

Fig 1: Positive cases percentage of pulmonary tuberculosis visiting NMCTH

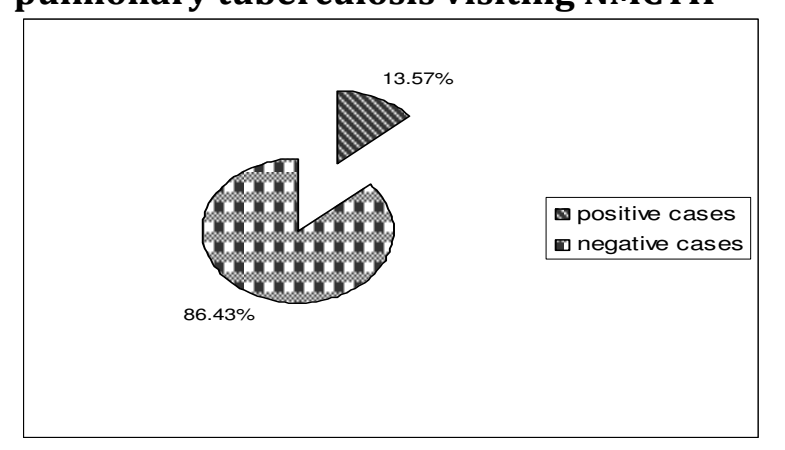

Table 1: Prevalence of pulmonary tuberculosis on the basis of gender

\begin{tabular}{|l|c|c|c|c|}
\hline Gender & $\begin{array}{c}\text { Positive } \\
(\%)\end{array}$ & $\begin{array}{c}\text { Negative } \\
(\%)\end{array}$ & Total & $\begin{array}{c}\text { P- } \\
\text { value }\end{array}$ \\
\hline Male & $\begin{array}{c}67 \\
(16.0)\end{array}$ & 351 & 418 & \multirow{2}{*}{$\mathrm{P}<0.05$} \\
\hline Female & $\begin{array}{c}18 \\
(8.7)\end{array}$ & 190 & 208 & \\
\cline { 1 - 4 } Total & $\begin{array}{c}85 \\
(13.6)\end{array}$ & 541 & 626 & \\
\hline
\end{tabular}

Table 2: Age wise prevalence of pulmonary tuberculosis

\begin{tabular}{|l|c|c|}
\hline Age group & Total & Positive (\%) \\
\hline Upto 20 yrs & 91 & $7(7.7)$ \\
\hline $21-40$ yrs & 215 & $27(12.6)$ \\
\hline $41-60$ yrs & 239 & $41(17.2)$ \\
\hline More than 60 yrs & 81 & $10(12.3)$ \\
\hline
\end{tabular}

Fig 2: The bacillary load in sputum among the positive cases of pulmonary tuberculosis

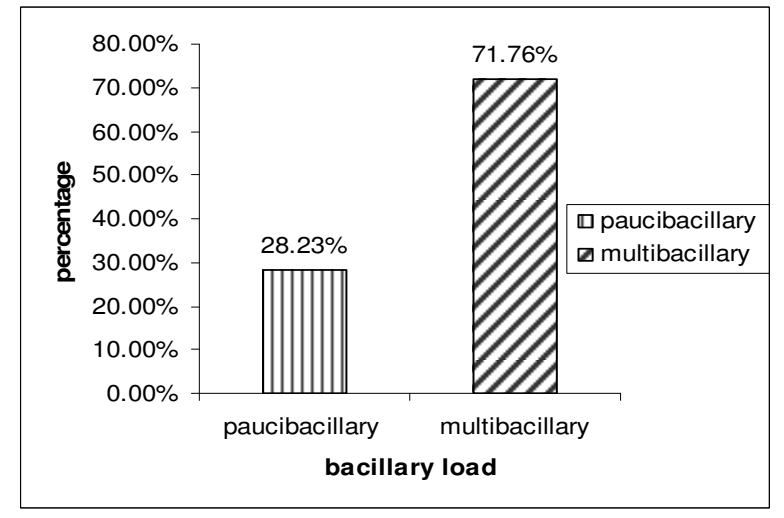

Among the positive case of pulmonary tuberculosis, the bacillary load in sputum as depicted in figure 2 which shows paucibacillary cases were lesser (28.2\%) than multibacillary cases $(71.8 \%)$.

In this study, the prevalence of pulmonary tuberculosis by Zn staining method was found to be $13.6 \%$ which was slightly higher than the nati- 
on's tuberculosis detection rate $(10.0 \%)$ but in agreement with findings of Rai et al, 2006 $(13.1 \%)$ in same setup during 2006. The slightly higher prevalence in the study than the nation's tuberculosis detection rate may be due to the more endemic area and easily accessible health care facilities compared to other remote Nepal. Higher prevalence was obtained in the study conducted by Negi et al in Dehli, 2005 (33.8\%), Ghatole et al in Solapur, 2005 (22.5\%), Prasanthi $\mathrm{K}$ and Kumari AR in Secunderbad, Gandhi Hospital, 2005 (50.0\%) and Shrestha et al in Dharan, 2005 (21.8\%).

The males are more infected (16.0\%) than female $(8.7 \%)$ which is statistically significant $(\mathrm{P}<0.05)$. Our study showed similar result to Rai et al in Birgunj (2006), Shrestha et al, 2005 in Dharan and Chern et al in Taiwan (2008). This does not reflect an increase in the occurrence of females to OPD is lower than male but may be due to more exposure of male to the environment for the sustenance of life, difference in socioeconomic status and culture factors. The male to female ratio of pulmonary tuberculosis in the study was 3.6, markedly greater than the report made by Sreeramareddy CT et al (2008) (2.29) elsewhere in Nepal. This may be due to the higher number of male in our study.

In the present study, maximum number of pulmonary tuberculosis cases was observed in age group of 41-60 years. This result is different from the study conducted by Shrestha et al in Dharan (2005) and Prasanthi K and Kumari AR in Gandhi Hospital, Secunderabad (2005). Dharan (2005) and Prasanthi K and Kumari AR in Gandhi Hospital, Secunderabad (2005). The prevalence of disease among different age group shows similar trend with finding at Rai et al (2006). In compare to younger one, age group 41-60 years are more infected by tuberculosis which could be due to impaired immune system in elderly people leading increase susceptibility to infectious diseases.

Of the positive cases, it was found that multibacillary cases are more $(71.8 \%)$ than the paucibacillary cases (28.2\%). Similar finding was also noticed in the study conducted by Prasanthi K and Kumari AR (2005). The multibacillary case was found to be more common may be due to the less health care awareness.

\section{CONCLUSION}

Accounting all the data together, we can conclude from our observation that, the prevalence is slightly higher than the Nation pulmonary tuberculosis detection rate $(10 \%)^{16}$, most commonly infecting males.

\section{ACKNOWLEDGEMENT}

We would like to extend our heartfelt gratitude to Asst. Prof. Deepak Bhargava, Asst. Prof. Biswajeet Samanta, Asst. Prof. Tina Mitra and all the staffs of Microbiology department National Medical college and teaching Hospital (NMCTH) also to Asst. Prof. Nirjala Laxmi Madhikarmi, Department of Biochemistry NMCTH, Birgunj for their kind support and co-operation.

\section{REFERENCES}

1. Bloom BR, Murray CJL. Tuberculosis: Commentary on a re-emergent killer. Science 1992; 257: 1055-64.

2. Agarwal KK. Editorial Post Graduate Medicine. Indian ed. 2001; $1: 7$.

3. Murray CJL, Styblok, Rouillon A. Tuberculosis in developing countries: burden, intervention and cost. Bull Int'l Union against Tuberc. Lungs Dis 1990; 65: 6-24. 
4. Dye C, Scheele S, Dolin P, Pathania V, Raviglione MC. Global burden of Tuberculosis estimated incidence, prevalence and mortality by country. J Am Med Assoc 1999; 282: 677-86.

5. Dolin P, Raviglione MC, Kahi A. A review of current epidemiological data and estimation of the future tuberculosis incidence and mortality. Geneva. WHO 1993.

6. Vasantha KR. Sputum smear examination. A view point. Indian J Tuberc 1995; 42: 135-7.

7. Barez MYC, Mendoza TM, Celada RS, Santos HR. Accuracy of AFB in relation to TB culture in detection of pulmonary tuberculosis. Phil J Microbiol infect Dis 1995; 24 (2): 33-6.

8. Somoskovi A, Hotaling JE, Fitzgerald M, Donnel D, Parsons LM, Salfinger M. Lessons fro a proficiency testing event for acid fast microscopy. Chest 2001; 120: 250-7.

9. Betty AF, Daniel FS, Alice SW. Bailey and Scott's Diagnostic Microbiology. $10^{\text {th }}$ edition. Mosby publishers; 1998; pp 715-43.

10. Sonnenwirth AC Jarett L. Gradwohl's clinical laboratory method and Diagnosis. B.I publication. New Dehli. $8^{\text {th }}$ edition. Vol 2. 1990; pp-1698.

11. Rai DR, Kshetry NT, Bhargava D, Pokhrel BM. Comparison of Ziehl-Neelsen staining microscopy and immunochromatographic tuberculosis test for diagnosis of pulmonary tuberculosis. J Institute of Medicine, Aug 2006, 28 (2): 15-18.

12. Laidlaw M. Mycobacterium: tubercle bacilli; In: Collee JG et al, editors. Pratical microbiology. Volume $12.13^{\text {th }}$ edition. London: Churchil Livingstone 1989.

13. Jain A, Bhargava A, Agrawal SK. A comparative study of two commonly used staining techniques for acid fast bacilli in clinical specimens. Int J Tub 2002; 49: 161-2.

14. Kantor IN, Kim SJ, Frieden T, Laszlo A, Lvelmo F, Norval PY, Rieder H, Valenzuelo P, Weyer K. Laboratory services in tuberculosis control. Microscopy part 2. World health organization, 1998.

15. Prasanthi K, Kumari AR. Efficacy of flurochrome stain in the diagnosis of pulmonary TB co-infected with HIV. Indian J med microbio 2005; 23 (3): 179-85.
16. HMG, Nepal, Ministry of Health. Department of Health service. Annual Report 2000/2001: 12445.

17. Negi SS, Khan SFB, Gupta S, Pasha ST, Khare S, Lal S. Comparison of the conventional diagnostic modalities, BACTEC culture and polymerase chain reaction test for diagnosis of tuberculosis. Indian J Med. Microbiology 2005; 23 (1): 29-33.

18. Ghatole M, Sable C, Kamale P, Kandle S, Jahagirdar V, Yemul V. Evaluation of Biphasic culture system for mycobacterial isolation from the sputum of patients with pulmonary tuberculosis. Indian J Med. Microbiology 2005; 23 (2): 111-13.

19. Shrestha D, Bhattacharya SK, Lekhak B, BC Rajendra Kumar. Evaluation of different staining techniques (Ziehl neelsen stain, Kinyoun stain, odified cold stain, Fluorochrome stain) for the diagnosis of pulmonary Tuberculosis. J Nepal Health Research Council 2005; Oct 3 (2): 8-16.

20. Chern JPS, Chen DR, Wen TH. Delayed Treatment of Diagnosed Pulmonary Tuberculosis in Taiwan. BMC Public Health 2008, 8: 236.

21. Sreeramareddy CT, Panduru KV, Verma SC, Joshi HS, Bates MN. Comparison of Pulmonary and extrapulmonary tuberculosis in Nepal- a hospital based retrospective study. BMC infectious diseases 2008; $\quad 8$ : 8 . (http://www.biomedcentral.com/14712334/8/8) 